\title{
Novel EphB4 Monoclonal Antibodies Modulate Angiogenesis and Inhibit Tumor Growth
}

\author{
Valery Krasnoperov, ${ }^{*}$ S. Ram Kumar, ${ }^{\dagger \neq}$ Eric Ley, ${ }^{\S}$ \\ Xiuqing $\mathrm{Li}^{\dagger}{ }^{\dagger}$ Jeffrey Scehnet, ${ }^{\dagger}$ Ren Liu, ${ }^{\dagger}$ \\ Sergey Zozulya, ${ }^{*}$ and Parkash S. Gill ${ }^{+\pi}$ \\ From Vasgene Thereapeutics Inc.," Los Angeles, and the \\ Departments of Pathology, ${ }^{\dagger}$ Surgery, ${ }^{\ddagger}$ Colorectal Surgery, ${ }^{\S}$ and

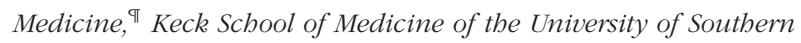 \\ California, Los Angeles, California
}

EphB4 receptor tyrosine kinase and its cognate ligand EphrinB2 regulate induction and maturation of newly forming vessels. Inhibition of their interaction arrests angiogenesis, vessel maturation, and pericyte recruitment. In addition, EphB4 is expressed in the vast majority of epithelial cancers and provides a survival advantage to most. Here, we describe two anti-EphB4 monoclonal antibodies that inhibit tumor angiogenesis and tumor growth by two distinct pathways. MAb131 binds to fibronectin-like domain 1 and induces degradation of human EphB4, but not murine EphB4. MAb131 inhibits human endothelial tube formation in vitro and growth of human tumors expressing EphB4 in vivo. In contrast, MAb47 targets fibronectin-like domain 2 of both human and murine EphB4 and does not alter EphB4 receptor levels, but inhibits angiogenesis and growth of both EphB4-positive and EphB4-negative tumors in a mouse s.c. xenograft model. Combination of MAb47 and bevacizumab enhances the antitumor activity and induces tumor regression. Indeed, humanized antibodies hAb47 and hAb131 showed similar affinity for EphB4 and retained efficacy in the inhibition of primary tumor development and experimental metastasis. (Am J Pathol 2010, 176:2029-2038; DOI: 10.2353/ajpath.2010.090755)

Angiogenesis is a process of new blood vessel sprouting from pre-existing vessels. This process includes primary capillary sprouting, branching, and remodeling into a mature blood vessel network. In the embryo, angiogenesis is preceded by vasculogenesis and represents one of the earliest processes in organ development. ${ }^{1,2}$ In adulthood, angiogenesis is induced at sites of tissue repair, tissue remodeling such as during menstruation, and in diseases constituting enhanced angiogenesis. ${ }^{1}$ Angiogenesis is also induced to varying degrees in cancers. ${ }^{1}$ Angiogenesis is triggered by protease-mediated degradation of matrix proteins releasing angiogenic factors such as vascular endothelial growth factor (VEGF), epidermal growth factor, and fibroblast growth factor, followed by the migration of endothelial cells to sprout new vessels. ${ }^{1,3}$ One critical step in vessel maturation is the interaction between arterial and venous capillaries leading to the fusion and lumen formation across the two cell types. This step is dependent on the interaction between EphB4 receptor tyrosine kinase expressed on venous endothelial cells and the trans-membrane ligand EphrinB2 expressed on arterial endothelial cells. ${ }^{4,5}$

EphB4 belongs to the Eph family, the largest family of receptor tyrosine kinases. To date, sixteen members of this receptor family have been characterized. ${ }^{6,7}$ Eph receptors are divided into two subgroups: EphA members (10 in number) that bind to ligands (EphrinA1-6) that lack transmembrane domains and localize to the cell membrane via glycosylphosphatidyl inositol linkage. EphB receptors (6 members) bind to ligands (EphrinB1-3) that contain a transmembrane domain. ${ }^{6,7}$ Receptor-ligand interaction leads to dimerization and phosphorylation of both receptor and ligand, resulting in bidirectional signaling. On stimulation with EphrinB2, Eph receptor "forward" signaling is triggered by autophosphorylation of its intracellular tyrosine kinase domain and downstream signaling. ${ }^{8-10}$ Ephrin-B "reverse" signaling also depends on tyrosine phosphorylation of the Ephrin cytoplasmic region. ${ }^{10}$

Targeted disruption of the EphB4 gene in mice is embryonically lethal secondary to the failure of blood vessel maturation and capillary arrest. ${ }^{11}$ EphrinB2 is the only known ligand for EphB4. Targeted disruption of the EphrinB2 gene has a phenotype similar to EphB4 knockout. 5,11 The role of EphB4 in adult vertebrates is not fully

Supported in part by National Cancer Institute (CA079218 to P.S.G.); and Woman's Cancer Research Foundation (to P.S.G.).

Accepted for publication December 11, 2009.

Supplemental material for this article can be found on http://ajp. amjpathol.org

Address reprint requests to Parkash S. Gill, Professor of Medicine and Pathology, University of Southern California, Health Sciences Campus, NOR 6332, 1441 Eastlake Avenue, Los Angeles, CA 90033. E-mail: parkashg@usc.edu. 
understood, in part because of a lack of appropriate conditional knock-out lines. EphB4 and EphrinB2 are induced in newly forming venous and arterial vessels, respectively, and are thus expected to play an important role in adult angiogenesis. ${ }^{9,12,13}$ This hypothesis is supported by the observation that the soluble monomeric form of the extracellular domain of EphB4 receptor (sEphB4) that blocks EphrinB2 interaction with its cognate receptors, blocks bidirectional signaling and inhibits angiogenesis at sites of neovascularization in the adult. ${ }^{14-16}$

Human tumor tissue analysis has shown that EphB4 is overexpressed in many tumor types: breast, ${ }^{17}$ colon, ${ }^{18-20}$ bladder, ${ }^{21}$ endometrium, ${ }^{22}$ head and neck, ${ }^{23}$ prostate, ${ }^{24,25}$ and ovary. ${ }^{26,27}$ EphB4 directly supports tumor cell survival by inhibiting apoptosis in many of these cancers. ${ }^{17,18,21-24,27}$ Tumor cell-expressed EphB4 also induces angiogenesis by direct interaction with EphrinB2 on tumor vessels. ${ }^{28}$ In this study, we describe novel EphB4-specific monoclonal antibodies that inhibit formation and maturation of newly forming vessels and inhibit tumor growth in vivo.

\section{Materials and Methods}

\section{Antibodies and Other Reagents}

Phosphotyrosine antibody (clone 4G10) was from Upstate (Lake Placid, NY). $\beta$-actin antibody was from Sigma Chemical Co. (St Louis, MO). Ki-67 antibody was from Abcam (Cambridge, MA). CD31, PDGFR, and NG2 antibodies were obtained from R\&D systems (Minneapolis, $\mathrm{MN}$ ). Hypoxyprobe-1 and hypoxyprobe antibody were from Chemicon International (Temecula, CA). TdT-mediated dUTP nick-end labeling (TUNEL) assay kit was from Roche (Piscataway, NJ).

\section{Cell Culture}

Human cancer cell line Hey was obtained from Dr. L. Dubeau of University of Southern California (USC, Los Angeles, CA). PC3M was from Dr. P. Roy-Burman of USC. KS-SLK was obtained from Dr. Rubinstein. ${ }^{29}$ MCF7, HT29, and SCC-15 were from American Type Culture Collection (Manassas, VA). All cells were propagated in RPMI-1640, supplemented with $10 \%$ Fetal Bovine Serum, 100 units $/ \mathrm{ml}$ of penicillin and $100 \mu \mathrm{g} / \mathrm{ml}$ streptomycin from Cellgro (Manassas, VA).

\section{Generation of Monoclonal Antibodies}

Extracellular domain of hEphB4 (aa 16-537) - hEphB4ECD was purified as previously described ${ }^{16}$ and used as an antigen. Five female Swiss Webster mice from Charles River Laboratories (Wilmington, MA) were immunized three times (every second week) intraperitoneally (i.p.) with $50 \mu \mathrm{g}$ of hEphB4-ECD per mouse. Antigen was injected as 1:1 mixture with Complete Freund's Adjuvant (Sigma, St. Louis, MO) in the first immunization, and with incomplete Freund's Adjuvant (Sigma) in the second and third doses. Mice were given a final boost with $20 \mu \mathrm{g}$ of hEphB4-ECD through tail-vein injection, and splenocytes were harvested 4 days later for fusion with myeloma cell line NSO from Lonza (Walkersville, MD). Hybridoma supernatants were screened for antibodies that immunoprecipitate hEphB4-ECD fused to alkaline phosphatase (AP). Selected monoclonal antibodies (MAb) were produced in ascites as previously described. ${ }^{30}$ MAbs were purified using three-step protocol: Ammonium sulfate precipitation, hydroxyapatite chromatography, followed by purification on anion-exchange resin. Estimated purity of MAbs was higher than 95\% based on HPLC analysis.

\section{Humanization of MAbs}

Both mouse MAb47 and mouse MAb131 were humanized using Composite Human Antibody technology (manuscript in preparation). Fc domain was replaced with human IgG1 subclass. Affinity of humanized antibodies for hEphB4-ECD was determined as described for murine clones. Chinese hamster ovarian cell lines stably expressing humanized antibodies (hAb47 and hAb131) were established and maintained in chemically defined serum-free medium (Irvine Scientific, Irvine, CA). Antibodies were purified from conditioned culture medium using Protein A-Agarose beads (GE health care, Piscataway, NJ).

\section{ELISA}

The set of recombinant EphB ECDs fused to AP were incubated with MAbs immobilized on Protein A-Agarose (100 ng/well) for 30 minutes. Unbound proteins were removed by washing three times with PBS and precipitated AP activity was detected with para-nitro-phenylphosphate. Negative controls included unrelated IgG (IgG control) or AP alone (No EphB). The set of recombinant EphA ECDs fused to FC from R\&D Systems (Minneapolis, MN) were immobilized (100 ng/well) overnight on 96-well plate from Thermo Scientific (Rockford, IL). Wells were blocked with $0.5 \%$ BSA in PBS for 40 minutes, followed by application of each monoclonal antibody at a concentration of $1 \mu \mathrm{g} / \mathrm{ml}$ for 40 minutes. Antibodies specifically bound to EphA receptor proteins were detected with anti-mouse-IgG-HRP (Thermo Scientific). Negative controls included wells without addition of EphA proteins ("No EphA") and wells without the addition of MAb47 or MAb131 ("No AB"). As positive control, EphA receptor proteins were detected with biotinylated EphrinA1-Fc/Streptavidin-HRP.

\section{Biotinylation}

Biotinylation of antibodies and mEphrinA1-Fc protein was performed using EZ-Link Biotin Hydrazide (Pierce, Rockford, IL) through oxidation of carbohydrate chains according to manufacturer's protocol. Biotinylated proteins were stored at $-80^{\circ} \mathrm{C}$ until use. Retention of the binding capacity of biotinylated proteins was confirmed using competition assay.

\section{Affinity of MAbs}

Biotinylated MAb47 and MAb131 were immobilized on Streptavidin Agarose from Thermo Scientific at final den- 
sity $10 \mu \mathrm{g}$ of IgG per $1 \mathrm{ml}$ of beads. Beads were then preblocked with $0.5 \%$ BSA in PBS and used for binding with extracellular fragment of human EphB4 fused to Alkaline Phosphatase (EphB4-AP). Sixteen different concentrations ranging from $50 \mathrm{pmol} / \mathrm{L}$ to $5000 \mathrm{pmol} / \mathrm{L}$ of EphB4-AP in triplicate were used to obtain a saturation plot. After binding for 40 minutes, all beads were washed three times with PBS followed by application of paranitro-phenyl-phosphate. Total values minus nonspecific background (no MAb added) were converted into coordinates of a Scatchard plot. ${ }^{31}$

\section{Endothelial Cell Tube Formation Assay}

$250 \mu$ l of Matrigel (Becton-Dickinson, Laguna Hills, CA) was placed in each well of an ice-cold 24-well plate. The plate was incubated at room temperature for 15 minutes and at $37^{\circ} \mathrm{C}$ for 30 minutes to allow Matrigel to solidify. ${ }^{17}$ $2 \times 10^{4}$ human umbilical vein endothelial cells in EGM2-MV medium from Clonetics (Allendale, $\mathrm{NJ}$ ) were mixed with $5 \mu \mathrm{g}$ of test MAb and plated in Matrigelcoated wells in triplicate. After 8 to 24 hours incubation, pictures were taken and analyzed by ImageJ software (National Institutes of Health, Bethesda, MD).

\section{Western Blot}

Proteins extracted from cells or tissue homogenate were resolved on $4 \%$ to $20 \%$ SDS-PAGE and transferred onto $0.2 \mu \mathrm{m}$ nitrocellulose membrane (BioRad, Hercules, CA). Membrane was blocked with $5 \%$ nonfat dry milk in TBS and $0.05 \%$ Tween-20 (TBST) for 40 minutes. The membrane was incubated with primary human EphB4 specific MAb265 at final concentration $0.5 \mu \mathrm{g} / \mathrm{ml}$ for 1 hour. Membrane was washed three times for 10 minutes each and incubated with secondary HRP-labeled anti-mouse antibody for 40 minutes. Finally, the membrane was washed three times with TBST and HRP signal was detected using chemiluminescent substrate. ${ }^{17}$

\section{Immunohistochemistry and Immunofluorescence}

Frozen sections of tumors $(5 \mu \mathrm{m})$ were fixed in $4 \%$ paraformaldehyde and washed in PBS. Endogenous peroxidase activity was blocked by incubation in $3 \% \mathrm{H}_{2} \mathrm{O}_{2}$ for 10 minutes. SuperBlock blocking buffer from Pierce (Rockford, IL) was used to prevent nonspecific binding. Sections were then incubated with primary antibody overnight at $4^{\circ} \mathrm{C}$, followed by corresponding secondary antibody for 30 minutes at room temperature. Antibody binding was localized with $A B C$ staining kit from Vector Laboratories (Burlingame, CA) ${ }^{17}$ In immunofluorescence assays, biotinylated secondary antibodies were used and the signal was detected with FITC-streptavidin. Nuclei were counterstained with 6-diamidino-2-phenylindole dihydrochloride hydrate (DAPI), and images were obtained with Olympus AX70 fluorescence microscope and Spot v2.2.2 digital imaging system. ${ }^{17}$

\section{Endocytosis}

Antibody mediated receptor endocytosis was examined on HT29 tumor cells cultured on BD Falcon 4-well culture slide in RPMI 1640 with $10 \%$ FBS. Cells were incubate with Cy5 labeled IgG, MAb47, or MAb131 (2 $\mu \mathrm{g} / \mathrm{ml})$ for 30 minutes on ice or $37^{\circ} \mathrm{C}$. Cells were washed in PBS and fixed with 4\% PFA for 20 minutes at room temperature, washed in PBS and mounted with VectaShield ${ }^{\circledR}$ mounting medium with DAPI (Vector Laboratories). Images were taken using Zeiss LSM510 confocal microscope.

\section{Matrigel Plug Assay in Vivo}

Growth factor-reduced Matrigel from BD Biosciences (Palo Alto, CA) was kept liquid on ice and reconstituted with either VEGF alone $(100 \mathrm{ng} / \mathrm{ml})$, VEGF $(100 \mathrm{ng} / \mathrm{ml})$ plus MAbs (10 $\mu \mathrm{g} / \mathrm{ml})$, or VEGF (100 $\mathrm{ng} / \mathrm{ml})$ plus sEphB4 (soluble extracellular domain of EphB4, $10 \mu \mathrm{g} / \mathrm{ml}$ ) as positive control for inhibition of angiogenesis. ${ }^{16}$ Matrigel $(0.5 \mathrm{ml}$ per injection) from each treatment group was injected in female Balb/C nu/nu mice (Charles River Laboratories) subcutaneously on each side of the midline of abdominal wall. On day 7 , plugs were excised under anesthesia, fixed in $10 \%$ formalin, embedded in paraffin, and sectioned (5- $\mu \mathrm{m}$ section) for histochemical analysis. Vascular identity of the infiltrating cells was established with CD31 immunostaining. The experiment was repeated three times. The vascularized area in each section was calculated using ImageJ software (National Institutes of Health, Bethesda, MD). ${ }^{17}$

\section{Murine Tumor Xenografts}

EphB4-positive tumor cell lines PC3M (a metastatic clone of PC3, a prostate carcinoma cell line, $1 \times 10^{6}$ cells), Hey (ovarian cancer cell line, $1 \times 10^{6}$ cells), HT29 (colorectal cancer cell line, $1 \times 10^{6}$ cells), SCC15 (head and neck cancer cell line, $5 \times 10^{6}$ cells) and MCF-7 (breast cancer cell line, $1 \times 10^{7}$ cells), and EphB4-negative KS-SLK (Kaposi sarcoma cell line, $2 \times 10^{6}$ cells) were injected subcutaneously on day 0 bilaterally in the flanks of 8-week-old Balb/C nu/nu mice (Charles River Laboratories). Beginning day 4 , tumor volumes were calculated as $0.52 \times a \times b^{2}$, where "a" and "b" are the largest and smallest lengths of the visible tumor. Animals were distributed into treatment and control groups ( $n=10$ tumors per group) such that the mean tumor volume of each group was comparable and the standard error (SE) between groups was minimal. Each group was treated by i.p. injection of antibody three times a week at a dose of $10 \mathrm{mg} / \mathrm{kg}$ once tumors were about $150 \mathrm{~mm}^{3}$. Treatment was continued until the end of the experiment when mice were sacrificed for tissue analysis. All procedures were approved by Institutional Animal Care and Use Committee and performed in accordance with the Animal Welfare Act regulations. 

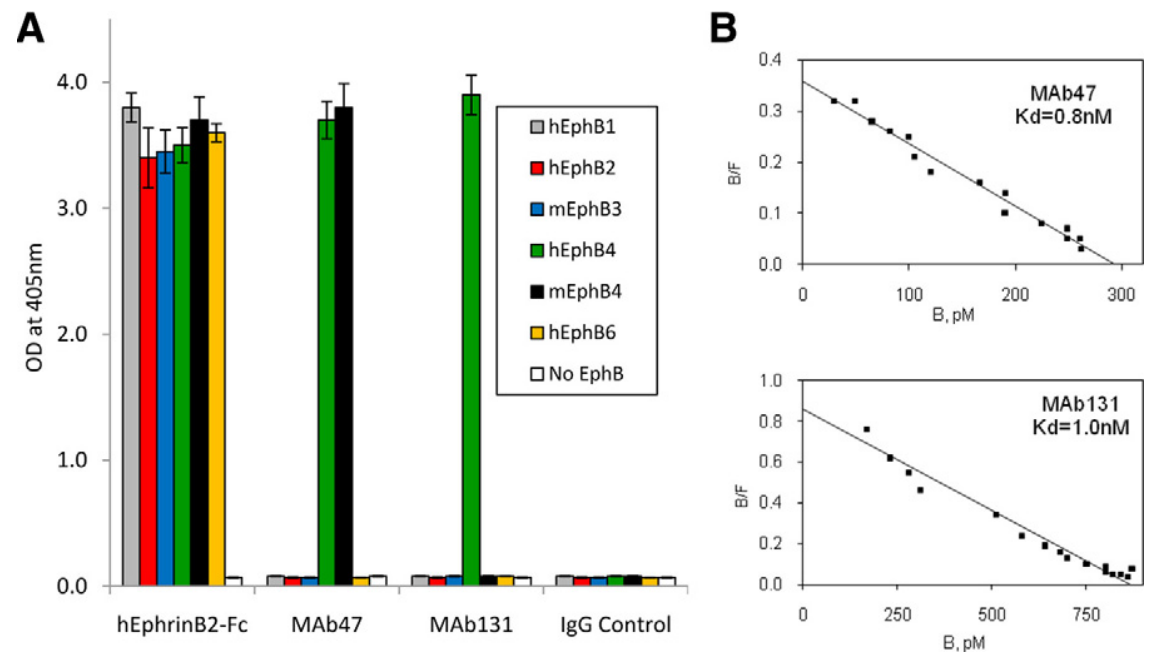

Figure 1. Binding of monoclonal antibodies to EphB4. A: MAbs were immobilized on Protein AAgarose beads and incubated with indicated recombinant EphB ECDs of human (h) or mouse (m) origin fused to AP. Negative controls included beads with $\mathrm{AP}$ alone (No EphB) and beads with unrelated IgG (IgG Control). As a positive control hEphrinB2-ECD fused to FC was used in place of antibodies. B: To measure antibody affinity, biotinylated MAb47 (top) or MAb131 (bottom) were immobilized on Streptavidin-Agarose beads. Different concentrations (50 to $5000 \mathrm{pmol} / \mathrm{L}$ ) of hEphB4-ECD-AP were applied to obtain saturation plot, nonspecific binding (no MAb added) values were subtracted and converted into coordinates of Scatchard plot.

\section{In Vivo Labeling of Functional Tumor Vasculature}

Rhodamine Ricinus communis agglutinin I (RCA) from Vector Laboratories (Burlingame, CA; $0.5 \mathrm{mg}$ in $100 \mu \mathrm{l}$ ) was injected into the tail vein and allowed to circulate for 7 minutes before the mice were euthanized. The tumors were harvested, frozen on dry ice, and stored at $-80^{\circ} \mathrm{C}$ until analysis. ${ }^{18}$

\section{Murine Tumor Metastatic Mode/s}

Male Balb/C nu/nu mice (6 to 7 weeks old) were anesthetized, the spleen was exposed via a left flank incision, and $1 \times 10^{7}$ HT29 cells were then slowly injected into the lower half of the splenic pulp. After 2 minutes, the hilum was ligated, splenectomy was performed, and the incision was closed. ${ }^{32}$ The animals were randomly assigned to four treatment groups (five mice per group): hAb47, hAb131, combination of both hAbs (at half of dose each), and PBS. Treatment was given three times a week i.p. starting from day 0 . After 39 days, mice were sacrificed and livers were evaluated for tumor metastasis.

\section{Results}

\section{Generation of Monoclonal Antibodies}

Anti-human EphB4 antibodies were generated in mice immunized with the extracellular domain of human EphB4. Despite the very high sequence homology between human and mouse EphB4 (89\% identity and 94\% similarity) within extracellular domain, we identified nearly 100 hybridomas producing distinct monoclonal antibodies to EphB4. Antibodies were screened for their ability to bind native protein - hEphB4-ECD by immunoprecipitation. Selected monoclonal antibodies were characterized in vitro and in vivo, epitopes were mapped, and affinity and isotypes were determined. Two antibodies were selected for further investigations.

\section{Specificity and Affinity of Monoclonal Antibodies to EphB4}

The specificity of MAb47 and MAb131 was determined using extracellular domains of EphB receptors fused to AP. Integrity of each protein was established for their binding to EphrinB2-Fc. MAb47 and MAb131 only bound to EphB4 (Figure 1A). MAb47 bound to both the murine and human EphB4, whereas MAb131 failed to bind mEphB4. Cross-reactivity of MAb47 and MAb131 to the receptors of EphA family was determined using EphA-Fc proteins. Integrity of EphA-Fc proteins was confirmed for their binding to biotinylated EphrinA-Fc. MAb47 and MAb131 did not bind any of the EphA receptor extracellular domain, confirming specificity to EphB4 (supplemental Figure S1 at http://ajp.ajppathol.org).

We next measured the affinity of both MAbs for human EphB4-ECD. Biotinylated antibodies were immobilized on Streptavidin-Agarose beads, and various concentrations of hEphB4-ECD fused to AP were applied. The data representing bound hEphB4-ECD-AP was converted to a Scatchard plot. A linear plot indicates a single binding site for each MAb. Both antibodies have a high binding affinity with a $\mathrm{kDa}$ of $0.8 \mathrm{nmol} / \mathrm{L}$ for MAb47 and $1.0 \mathrm{nmol} / \mathrm{L}$ for MAb131 (Figure 1B).

The extracellular portion of EphB4 receptor consists of 4 domains - starting with the N-terminal EphrinB2 ligandbinding globular domain, followed by a cysteine rich-domain and two fibronectin III like repeat domains refered to as $\mathrm{FN}-1$ and $\mathrm{FN}-2$. MAb47 is an IgG3 subclass antibody that recognizes FN-2 repeat domain, whereas MAb131 is an IgG1 that recognizes the $\mathrm{FN}-1$ domain (data not shown).

\section{Endothelial Tube Formation Assay}

Endothelial cells have the ability to form tube-like structures when plated on Matrigel-coated wells in the presence of growth factors such as VEGF or fibroblast growth factor. ${ }^{16}$ Human umbilical vein endothelial cells when cultured on 
A

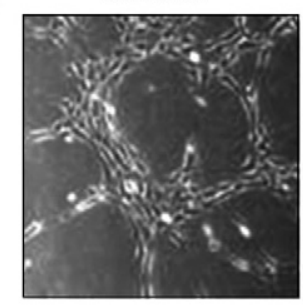

$\operatorname{lgG}$

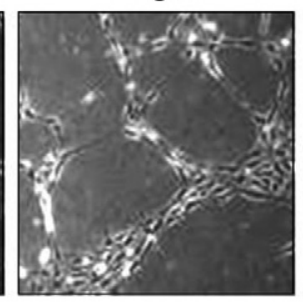

sEphB4

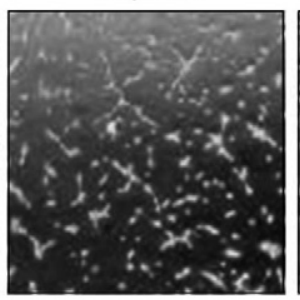

MAb47

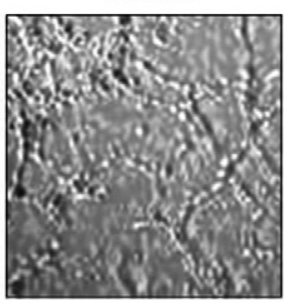

MAb131

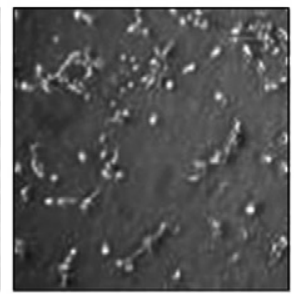

B
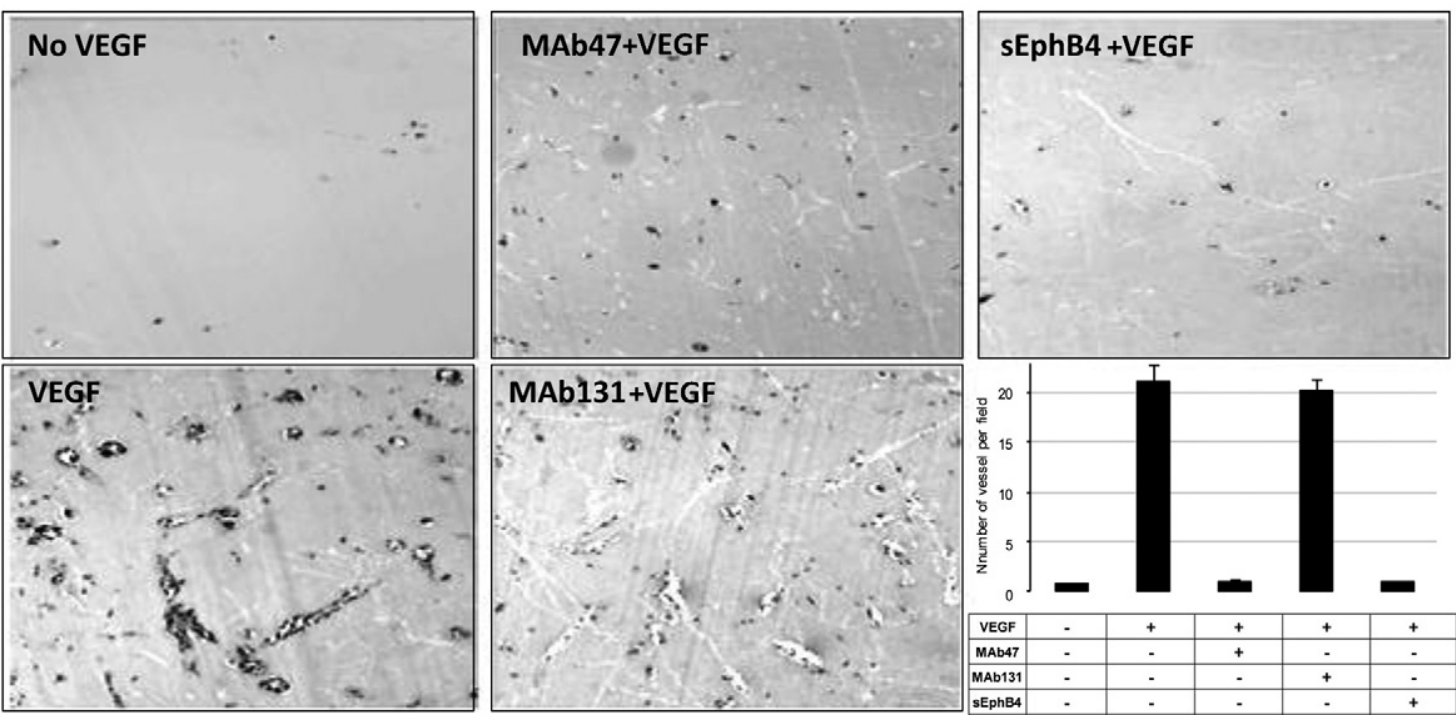

Figure 2. Effect of antibodies on human umbilical vein endothelial tube formation assay and Matrigel plug assays: A: Human umbilical vein endothelial cells (20,000 per well) were premixed with test compounds at the final concentration of $10 \mu \mathrm{g} / \mathrm{ml}$ and plated on matrigel coated wells. Negative controls included PBS or unrelated mouse IgG. Positive control consisted of soluble EphB4 (sEphB4) applied at a concentration of $5 \mu \mathrm{g} / \mathrm{ml}(\times 20)$. Pictures were taken using a Bioquant Image Analysis system. B: Matrigel impregnated with test compounds $(0.5 \mathrm{ml})$ was implanted in mouse abdominal wall. Plugs were harvested on day 7 and analyzed for vessel density $(\times 10)$. Quantification of vessel density was done using image analysis system. Data are presented as mean \pm SE.

Matrigel-coated wells in the presence of $50 \mathrm{ng} / \mathrm{ml}$ VEGFcontaining medium form multiple tube-like structures (Figure 2A). sEphB4 protein inhibits tube formation and was used as a positive control. ${ }^{16}$ Both MAb131 and MAb47 significantly inhibit tube formation, although the effect of MAb47 was less pronounced than MAb131 (Figure 2A). Tube formation was not affected by unrelated IgG. No cellular toxicity was observed under any of the conditions.

\section{MAbs and Vascularization of Matrigel Plugs in Vivo}

To characterize the antiangiogenic properties of MAbs in vivo, we performed Matrigel plug assays in mice. Matrigel plugs without growth factor had virtually no vascular structures and were used as negative control for angiogenesis (Figure 2B). Matrigel plugs supplemented with VEGF had extensive angiogenesis with prominent lumen in several vessels. Matrigel plugs with VEGF and MAb131 showed a vascular pattern similar to VEGF only. This was not surprising considering the lack of ability of MAb131 to bind mouse EphB4. In contrast, Matrigel plugs containing VEGF and MAb47 had markedly reduced vascularization (Figure 2B), comparable with the plugs premixed with sEphB4 or no growth factor. On average, MAb47 decreased vessel formation by 20 -fold. Thus MAb47 has potent inhibitory activity in vivo on migration of endothelial cells and formation of vascular structures.

\section{Effect of MAbs on Human Tumor Xenografts}

We studied the effect of MAbs in vivo using a human tumor xenograft model. Several EphB4-positive human tumor cell lines were implanted in mice. Treatment began once the tumors were established with sizes around 100 to $200 \mathrm{~mm}^{3}$, and the treatment was continued for the duration of the study (Figure 3A). Mice bearing PC3M tumor xenografts treated with MAb47 had a tumor volume of $70( \pm 20) \mathrm{mm}^{3}$ after four weeks, compared with $1350( \pm 150) \mathrm{mm}^{3}$ in the control group (5\% of control). A similar effect was observed with other EphB4-positive tumors including head and neck squamous carcinoma cell line SCC15 (14\% of control), colon cancer cell line HT29 (20\% of control), and ovarian carcinoma cell line Hey (17\% of control; Figure 3A). MAb131 also showed a significant reduction in tumor growth in all of the EphB4-positive tumor cell lines studied. Head and neck squamous carcinoma SCC15 was less sensitive to MAb131 treatment with tumor volume of $37 \%$ compared with the controls. SCC15 also grew to a much smaller volume in control animals compared with other tumor types reaching a volume of $380 \pm 30 \mathrm{~mm}^{3}$ at the termination of this experiment (Figure 3B). Rate of tumor growth may possibly influence response to the antibody therapy. 
A

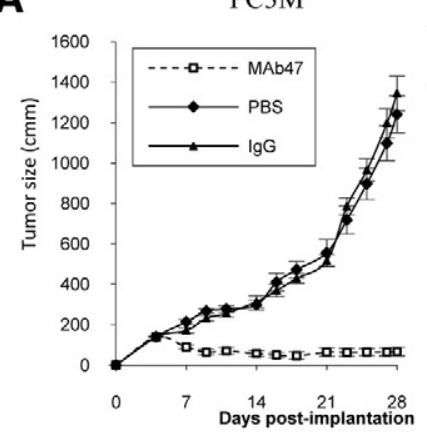

HT29

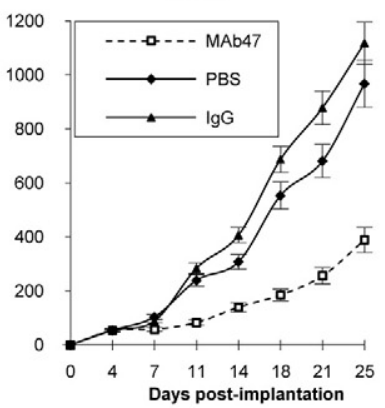

SCC15

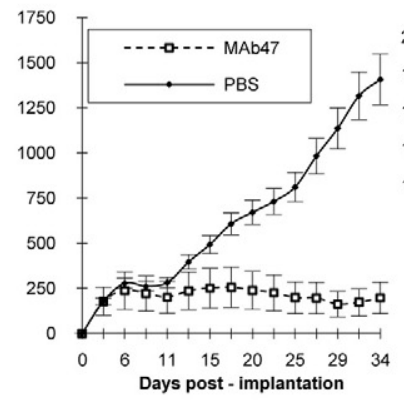

SCC15

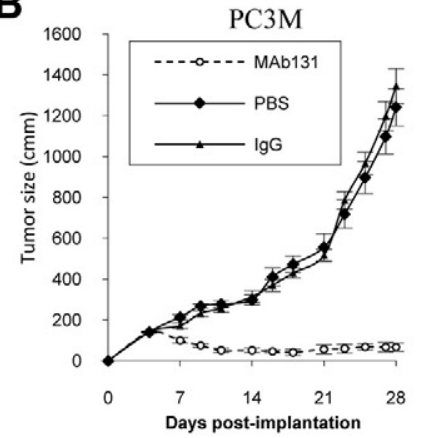

HT29

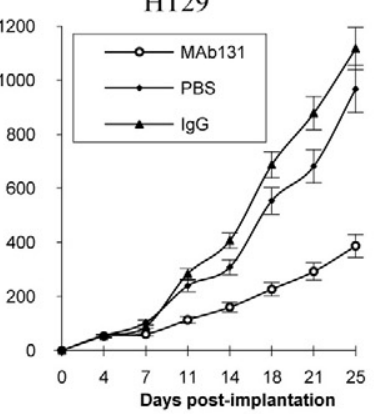

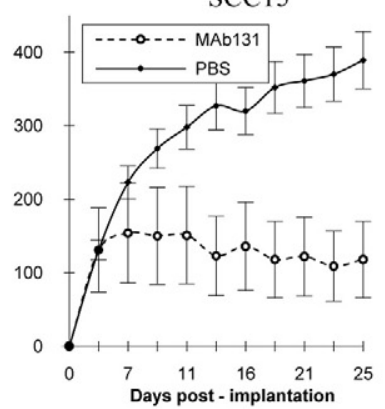

Hey

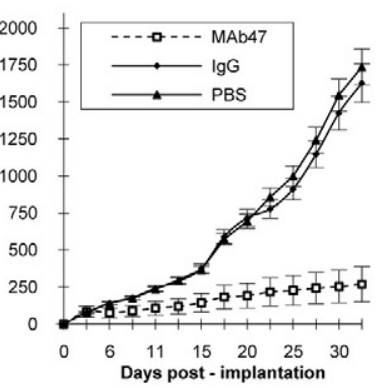

C

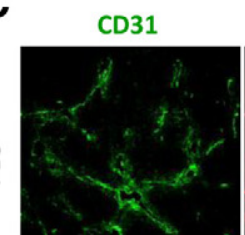

RCA

Merged
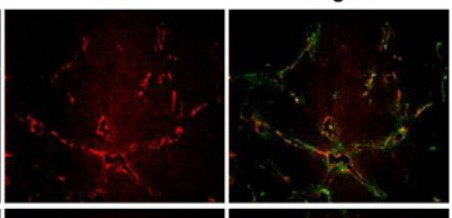

章
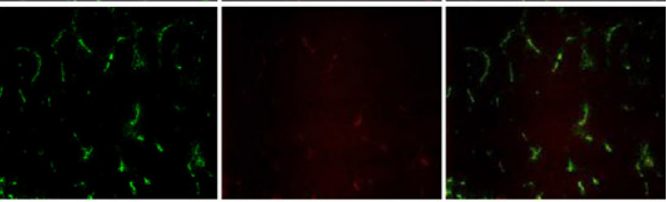

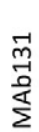
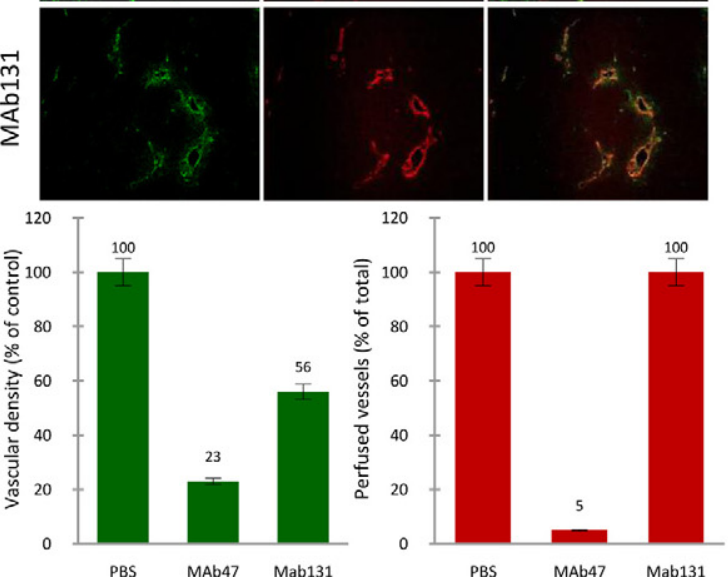

\section{D}
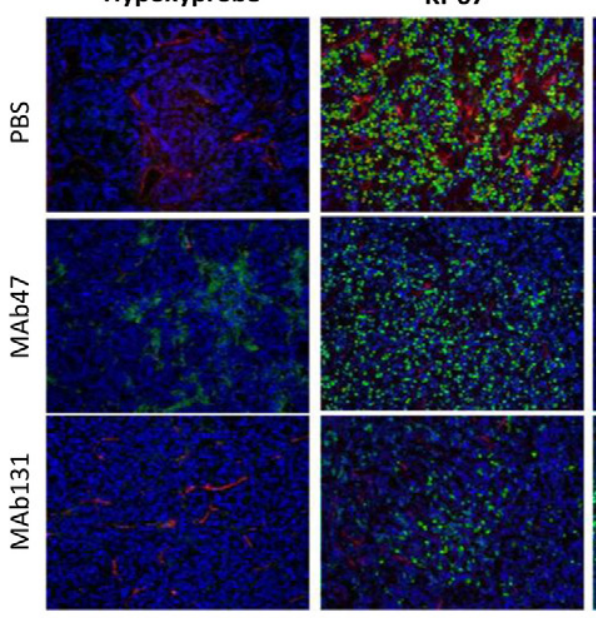

Hey
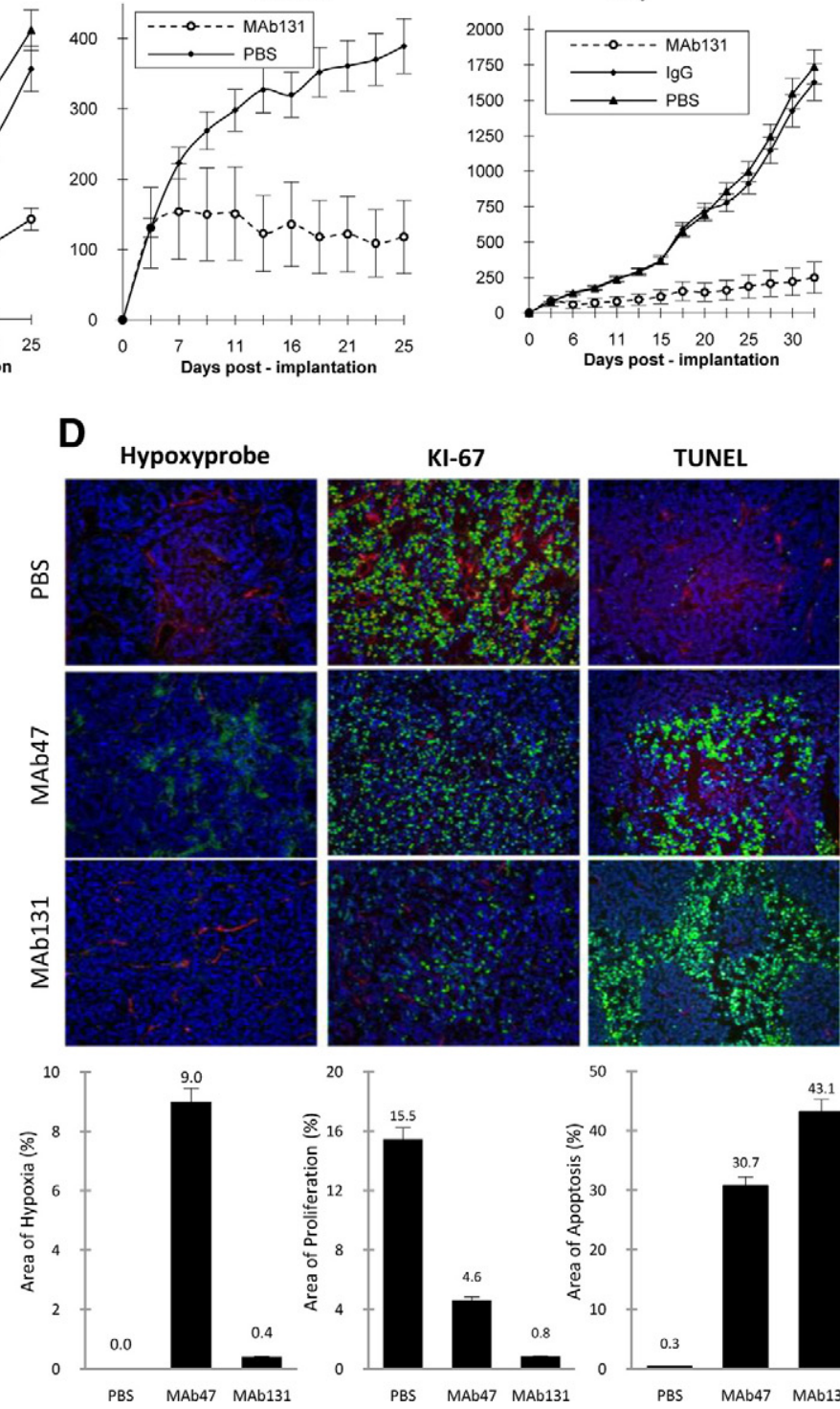

were randomized to different treatment groups. Tumor volumes over time after treatment with MAb47 (A) or MAb131 (B) are shown. Controls include PBS or isotype specific IgG. C: Analysis of HT29 tumor tissues harvested after therapy. Representative data for vessel density (CD31 staining in green), vessel perfusion (RCA in red), and merged images $(\times 20)$ are shown. Quantification of vessel density and perfusion was done using Bioquant image analysis. Data are presented as mean \pm SE. D: Tissue analysis of HT29 tumors was performed for areas of hypoxia (green), proliferative index by Ki-67 staining (green), and apoptosis by TUNEL assay (green). Perfused vessels were identified by RCA localization (red). Quantification of areas of hypoxia, proliferation, and apoptosis was done using Bioquant image analysis $(\times 20)$. Data are presented as mean \pm SE. 
A

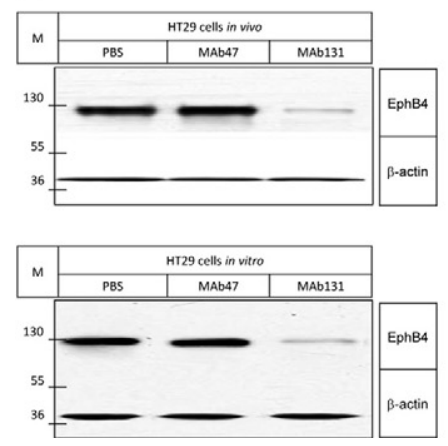

B

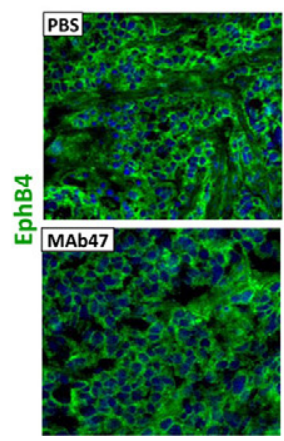

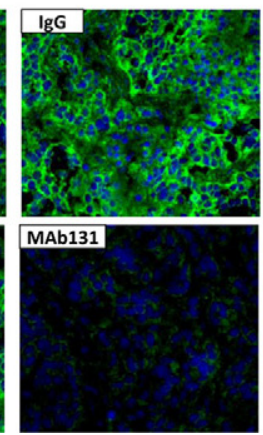

$\lg G$

C

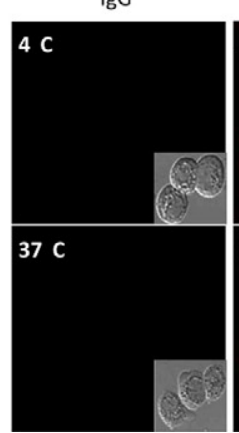

MAb47

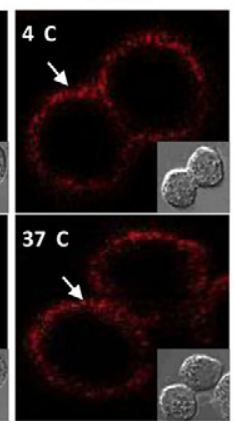

MAb131

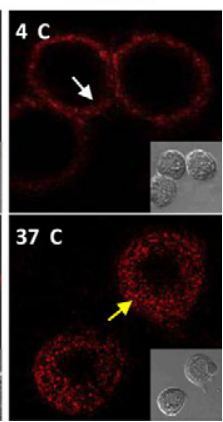

Figure 4. EphB4 degradation and endocytosis after antibody treatment. A: Western blots for level of EphB4 in HT29 tumor tissue harvested at the end of in vivo experiments (top) or in HT29 cells treated in vitro at a dose of $10 \mu \mathrm{g} / \mathrm{ml}$ for 12 hours (bottom) are shown. "M" represents molecular mass marker in kDa. B: Immunofluorescence assay for EphB4 localization (green) and nuclear staining with DAPI (blue) was performed on HT29 tumor xenografts at the end of the antibody therapy. C: HT29 cells were exposed to Cy5 labeled IgG, MAb47, or MAb131 at $4^{\circ} \mathrm{C}$ or $37^{\circ} \mathrm{C}$ for 30 minutes. EphB4 was localized (red) using confocal microscope. MAb131 at $37^{\circ} \mathrm{C}$ induces endocytosis (yellow arrow), while MAb47 does not (white arrow). No endocytosis is observed at $4{ }^{\circ} \mathrm{C}$ (white arrows) with eithor antibody. Cells imaging using differential interference contrast are shown in the insets.

\section{Tumor Angiogenesis and Hypoxia}

Tumor vessel density and matching perfusion were analyzed by concurrent endothelial cell staining with CD31 and perfusion analysis by RCA binding to the luminal surface of the perfused vessels. Control tumors were well vascularized with high vessel density and matching perfusion (Figure 3C top row). The vessels of MAb47-treated mice appeared different (Figure $3 \mathrm{C}$ middle row) from that of controls and MAb131-treated tumors. The tumor blood vessels in MAb47-treated group were fewer (23\% of control), and the majority lacked perfusion (only $5 \%$ of total vessels were perfused). Blood vessel density in MAb131treated group was reduced to $56 \%$ of control, however vessel lumens were large and all of them were well perfused (Figure 3C bottom row). Consistent with reduced perfusion, there was a marked increase in hypoxic regions in tumors treated with MAb47 (9\% of the area analyzed) compared with control tumors (Figure 3D).

\section{Proliferation Index and Apoptosis}

Cell proliferation index was examined using Ki-67 immunostaining. Control tumors showed a high rate of tumor cell proliferation (15.5\% of tumor area; Figure 3D). Tumors treated with MAb47 showed fewer (4.6\%) Ki-67positive cells, whereas treatment with MAb131 resulted in further reduction in cell proliferation ( $0.8 \%$ of total area). Analysis of apoptosis with TUNEL staining showed low positivity in control group ( $0.3 \%$ of tumor area) and marked increase with antibody treatment: $30.7 \%$ and 43.1\% for MAb47 and MAb131, respectively (Figure 3D).

\section{EphB4 Endocytosis and Degradation}

We investigated EphB4 levels in control and antibodytreated HT29 tumor tissues. Control tumors expressed high levels of EphB4 and treatment with MAb47 had no impact on EphB4 expression (Figure 4A top). In contrast, tumors in mice treated with MAb131 showed marked reduction in EphB4 levels, similar to cells treated in vitro with MAb131 (Figure 4A bottom). Loss of EphB4 in tumors treated with MAb131 was confirmed by immunostaining (Figure 4B). In vitro analysis of HT29 cells treated with MAb131 showed endocytosis of EphB4 receptor at $37^{\circ} \mathrm{C}$ but not $4^{\circ} \mathrm{C}$ (Figure $4 \mathrm{C}$ ). MAb47 and control IgG did not induce endocytosis.

\section{Antibody Activity in EphB4 Negative Tumors in Vivo}

Because MAb47 recognizes murine EphB4 and has a more pronounced antiangiogenic effect than MAb131 in vivo, we hypothesized that MAb47 would inhibit growth of EphB4-negative tumors as well, whereas MAb131 would only affect human tumor xenografts that express EphB4. To validate this hypothesis, we conducted human tumor xenograft studies with EphB4-negative human Kaposi's sarcoma tumor cell line KS-SLK in athymic mice (Figure 5A). MAb131 had no effect on tumor xenografts. Average tumor size of $1426 \pm 109 \mathrm{~mm}^{3}$ did not differ from that of control tumors, $1593 \pm 220 \mathrm{~mm}^{3}$ ( $P$ value $>0.05$, NS). In contrast, MAb47-treated group demonstrated marked decrease in tumor size to $250 \pm 80 \mathrm{~mm}^{3}(17 \%$ on day 32). Similar to MAb47-treated EphB4-positive tumors, MAb47-treated SLK tumors had fewer blood vessels with altered morphology and reduced perfusion, with large areas of hypoxia (data not shown). No difference was found between MAb131-treated and control tumors in vascularization, apoptosis, proliferation, or hypoxia marker (data not shown).

\section{Activity of MAb47 F(ab) $)_{2}$ and MAb131F(ab) in Vivo}

We wished to determine whether the antibody function in vivo was dependent on $\mathrm{Fc}$ function or was solely attributable to modulation of the target protein EphB4. We thus generated $F(a b)_{2}$ fragments of the antibody by pepsin digestion. Integrity of isolated and purified $\mathrm{F}(\mathrm{ab})_{2}$ fragments was confirmed by competition assay 
A
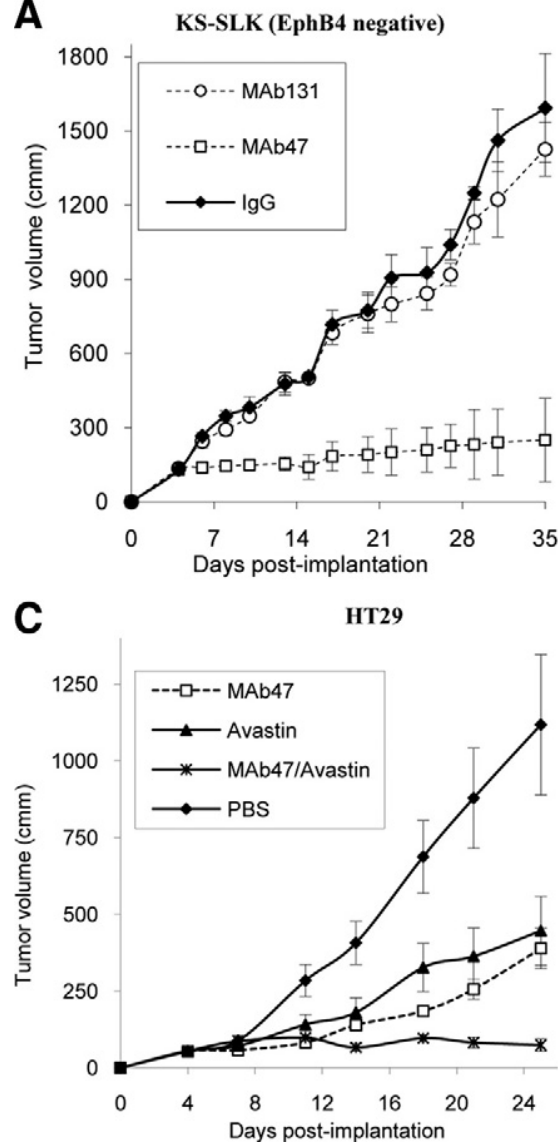

B

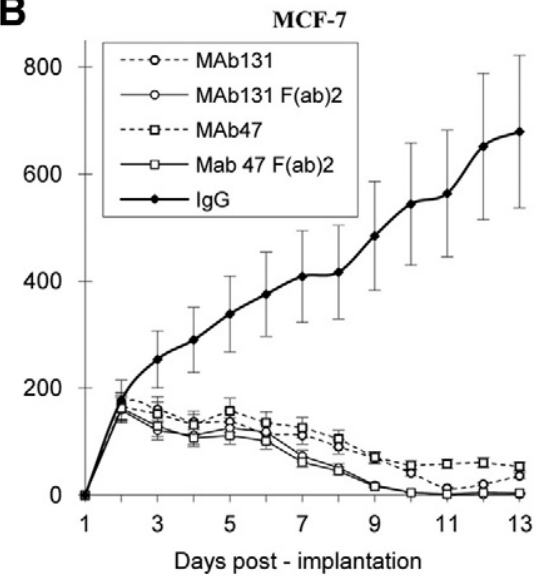

D

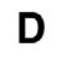

D

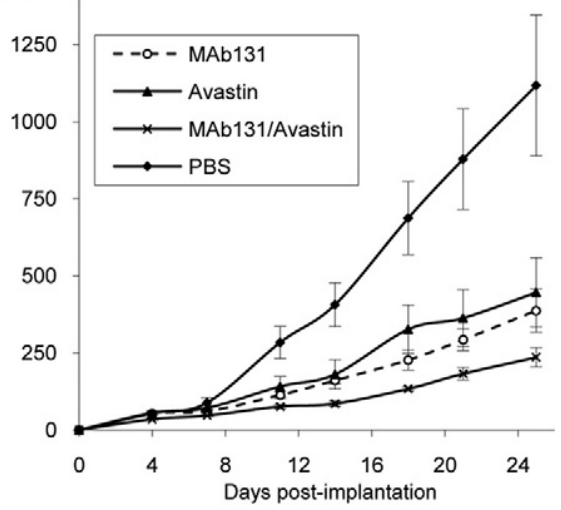

Figure 5. A: $M A b$ therapy of EphB4-negative tumor xenografts. EphB4-negative KS-SLK cell line was implanted and tumor xenografts were treated with MAb47, MAb131, or IgG as in Figure 3, A and B. Tumor volumes were measured over time. B: Activity of full-length EphB4 antibodies (twice a week i.p.) or $\mathrm{F}(\mathrm{ab})_{2}$ fragments (three times a week i.p.) were tested in mice bearing HT29 tumors as in Figure 3, A and B. C and D: Combination studies of EphB4 antibodies and VEGF antibody. HT29 tumor-bearing mice were assigned to treatment groups of MAb47, MAb131, and VEGF antibody (Avastin) each one alone, or combination of Avastin plus MAb47 or Avastin plus MAb131. In combination studies, the dose of each antibody was reduced by $50 \%(5 \mathrm{mg} / \mathrm{kg})$. Tumor volumes were measured over time. between whole undigested IgG and corresponding $\mathrm{F}(\mathrm{ab})_{2}$ for EphB4 binding (See Supplemental Figure S2 at http://ajp.amjpathol.org). The $\mathrm{F}(\mathrm{ab})_{2}$ fragments were fully functional and competed with parental full-length IgGs at equimolar ratio. $\mathrm{F}(\mathrm{ab})_{2}$ have a shorter half life in blood stream compared with full-length antibody. To compensate for the shorter half life, we administered $F(a b)_{2}$ fragments three times a week. $F(a b)_{2}$ fragments of both antibodies showed significant inhibition of tumor growth in EphB4-positive MCF-7 human breast cancer cells in vivo (Figure $5 \mathrm{~B}$ ) indicating that the primary mechanism underlying antibody function is modulation of target protein EphB4.

\section{Combinatorial Studies: Anti-EphB4 Antibodies and Avastin}

Avastin (Bevacizumab), a humanized monoclonal antibody generated against VEGF, is active in various human tumor xenograft models and in human clinical trials when combined with other agents. ${ }^{33}$ Avastin binds only to human VEGF and therefore in the mouse xenograft models would only target VEGF produced by human tumor cells. ${ }^{33}$ Because the steps in angiogenesis modulated by EphB4/EphrinB2 are distinct from those affected by VEGF, we tested the combined effect of EphB4 antibodies and Avastin on HT29 tumor xenografts. Whereas control tumors grew to $1120 \pm 228 \mathrm{~mm}^{3}$ by day 25 , Avastin-,
MAb47-, and MAb131-treated tumors were $447 \mathrm{~mm}^{3}$ (60\% reduction), $389 \mathrm{~mm}^{3}$ (65\% reduction), and 387 $\mathrm{mm}^{3}$ (65\% reduction), respectively (Figure 5, C and D). Combination of Avastin and MAb131 treatment resulted in an average tumor volume of $236 \mathrm{~mm}^{3}$ (79\% reduction). Combination of Avastin and MAb47 treatment resulted in a tumor volume of $75 \pm 20 \mathrm{~mm}^{3}$, which was smaller than the volume at initiation of therapy.

\section{Activity of Humanized MAbs in Vivo}

To minimize immune response during human therapy both MAbs 47 and 131 were humanized (hAb47 and hAb131 accordingly) using Composite Human Antibody technology, and expressed in Chinese hamster ovarian mammalian cells in serum-free conditions. Both antibodies showed affinity similar to the parental murine antibodies, and competed (1:1 ratio) with the parental murine antibody in vitro (data not shown). We studied the effect of hAb47 and hAb131 in vivo on murine tumor xenografts. Twenty-four days after implantation, hAb47 and hAb131-treated HT29 tumors had tumor growth reduced to $64 \%$ and $75 \%$, respectively, compared with control tumors (Figure 6A).

We also determined the activity of hAbs in tumor metastasis. Liver metastases after splenic pulp injection of HT29 colorectal cancer cell line was studied, and both humanized antibodies were tested alone and in combination (Figure 6B). Livers harvested on day 39 showed 
A
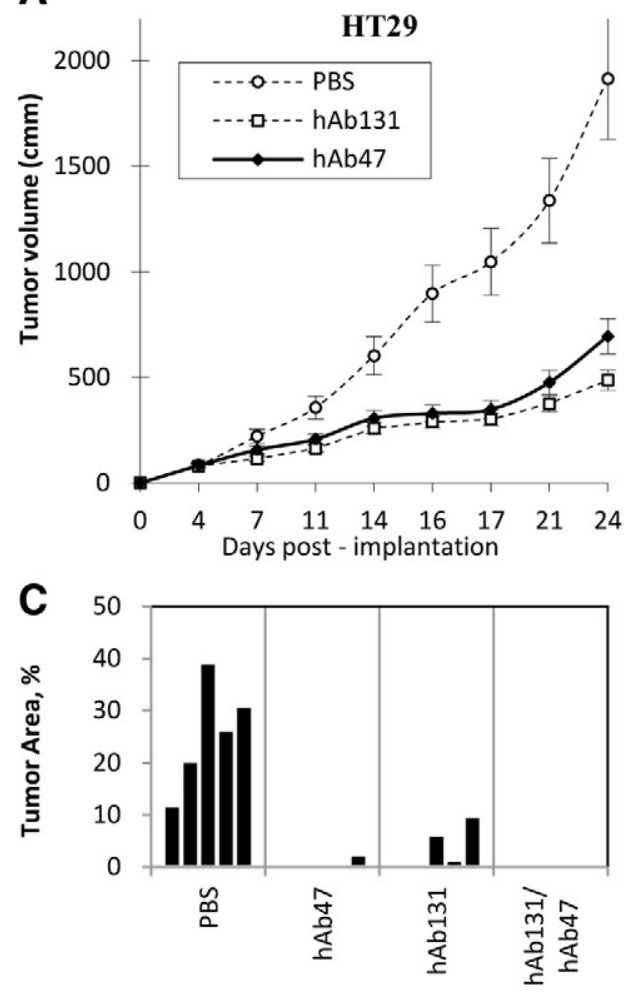

B

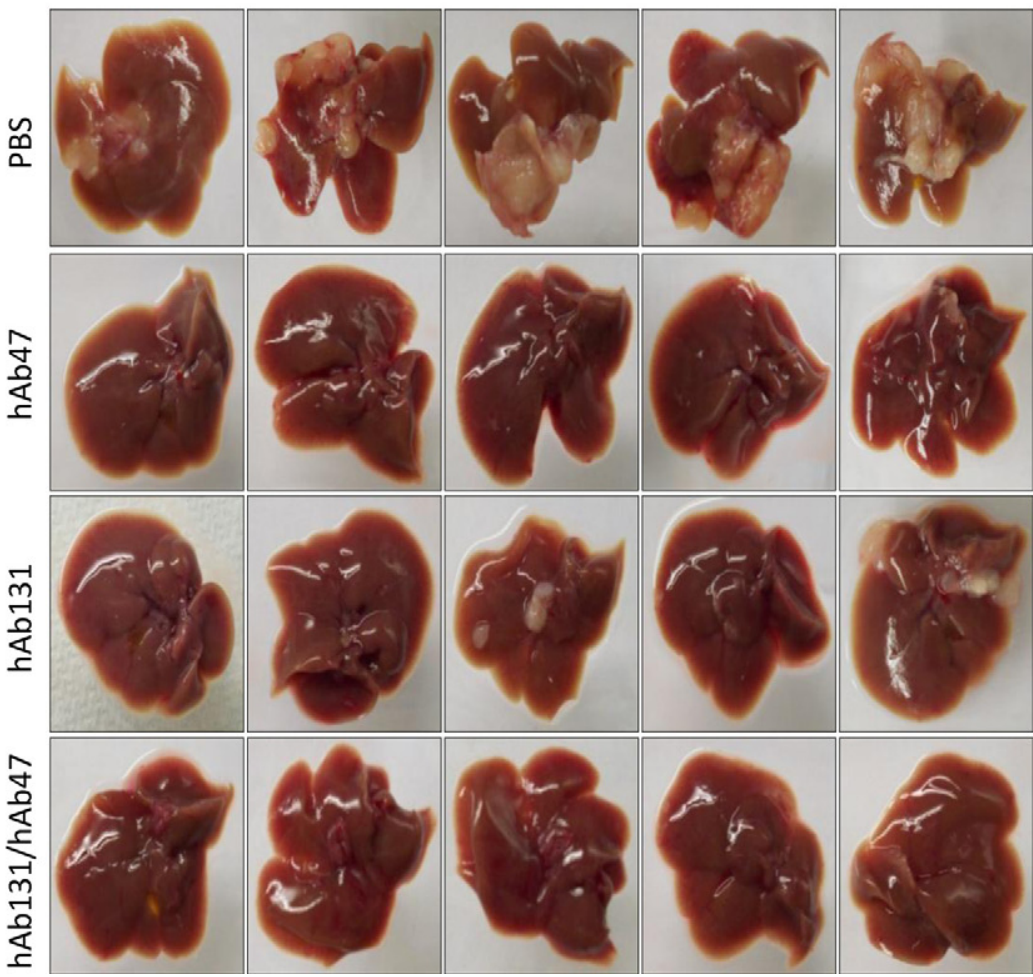

Figure 6. Activity of Humanized MAbs in vivo. A: HT29 tumor xenografts in nu/nu mice were treated with either hAb47 or hAb131 i.p. three times a week, at the dose of $10 \mathrm{mg} / \mathrm{kg}$. Tumor volumes were measured over time. B: Activity of humanized EphB4 antibodies in liver metastasis after intrasplenic injection of HT29 colon ca cell line. hAb47 and hAb131 treatment was administered i.p. three times a week. Images of livers harvested at the end of the study from each treatment group are shown. C: Area of the liver occupied by the tumor is provided.

metastases in all five control mice covering $12 \%$ to $39 \%$ of the external liver surface. hAb47-treated group showed tumors in one of five livers covering $2.3 \%$ of the liver surface. hAb131-treated group also showed tumors in three of five livers covering $1.3 \%$ to $9.7 \%$ of the liver surface. Mice treated with the combination of hAb47 and hAb131 showed no tumor metastasis in the liver (Figure 6, B and C).

\section{Discussion}

The role played by EphB4 in tumor biology is a subject of intense investigation. Similar to its effects at other sites of neovascularization in the adult, the interaction between EphrinB2 and EphB4 expressed on tumor vascular endothelial cells likely plays a critical role in tumor angiogenesis and growth. In addition, EphB4 aberrantly expressed on tumor cells themselves can interact with endothelial cell EphrinB2, further promoting tumor angiogenesis. Independent of its angiogenic effects, we have shown that EphB4 on tumor cells provides direct survival advantage rendering tumors more aggressive and favoring tumor metastases. Antibodies targeting the EphB4 pathway, therefore, have the potential to inhibit tumor growth via multiple mechanisms.

We generated EphB4-specific monoclonal antibodies targeting the extracellular domain of EphB4. These antibodies bound EphB4 with high affinity (around $1 \mathrm{nmol} / \mathrm{L}$ ) but did not recognize any other member of the Eph family of receptors. Antibodies bound distinct domains of the EphB4 re- ceptor and demonstrated different biological functions. MAb47 recognizes both human and mouse EphB4 and inhibits angiogenesis and vessel maturation. Treatment with MAb47 not only blocks growth factor-induced recruitment of endothelial cells thus reducing the number of blood vessels, but also inhibits organization of vascular structures and lumen formation resulting in formation of immature vascular structures. In addition, these newly formed vessels are not perfused, indicating lack of integration with primary vascular system, mimicking the EphB4-knockout phenotype of capillary arrest without vessel maturation. Because MAb47 does not alter EphB4 levels, we speculate that it modifies vascular response by targeting EphB4-EphrinB2 interaction or interaction of EphB4 with other proteins. Because of its cross-reactivity to murine EphB4, MAb47 was active in xenografts of human tumors expressing EphB4 and those lacking EphB4. In MAb47-treated animals the tumors had large areas of hypoxia accompanied by tumor cell apoptosis and growth inhibition.

MAb131 induces hEphB4 degradation, and inhibits human endothelial cell organization into tube-like structures in vitro, indicating antiangiogenic activity. MAb131 lacks binding to mouse EphB4 and thus could not be evaluated in mouse models of angiogenesis or spontaneous mouse tumor models. MAb131, however, had profound antitumor activity against xenografts of human tumors that express EphB4. Treatment with MAb131 induced large areas of apoptosis and reduced tumor cell proliferation, and we 
speculate that these events represent a consequence of direct tumor cell EphB4 modulation and decrease in EphB4 levels. There was a much less significant reduction in tumor angiogenesis, likely from interference with interaction between human tumor cell EphB4 and murine endothelial cell EphrinB2. It is, therefore, anticipated that MAb131 may be even more active in human trials where it has the ability to target EphB4 expressed both on tumor cells and the vascular endothelium. Degradation of tumor cell EphB4 can directly inhibit tumor growth similar to the effect seen in xenografts. In addition, akin to the effects seen with MAb47 in mice, MAb131 will also exhibit a profound antiangiogenic effect by inhibiting the interaction between tumor cell EphB4 and endothelial EphrinB2, as well as endothelial cell expressed EphB4 and EphrinB2.

EphB4 antibodies also inhibit tumor cell colonization in experimental metastasis model using intrasplenic inoculation of tumor cells to facilitate liver metastasis. Both MAb131 and MAb47 have biological activity in a metastatic model of colon cancer with enhanced efficacy when combined, indicating that the two antibodies have distinct mechanisms of action. The functions of MAb47 and MAb131 result from direct receptor targeting as evidenced by the efficacy of their $\mathrm{F}(\mathrm{ab})_{2}$ fragments. In addition, because EphB4-EphrinB2 interaction affects distinct functions in vascular biology compared with VEGF, combination of antibodies targeting VEGF and EphB4 results in enhanced efficacy.

In summary, we describe two EphB4 monoclonal antibodies that target different EphB4 domains and act via different mechanisms of action. Humanized Ab47 and humanized Ab131 maintain their affinity to EphB4 and exhibit significant antitumor activity in mouse models, and, thus, are candidates for clinical application.

\section{References}

1. Griffioen AW, Molema G: Angiogenesis: potentials for pharmacologic intervention in the treatment of cancer, cardiovascular diseases, and chronic inflammation. Pharmacol Rev 2000, 52:237-268

2. Yancopoulos GD, Davis S, Gale NW, Rudge JS, Wiegand SJ, Holash $\mathrm{J}$ : Vascular-specific growth factors and blood vessel formation. Nature 2000, 407:242-248

3. Kerbel RS: Tumor angiogenesis. N Engl J Med 2008, 358:2039-2049

4. Brantley-Sieders DM, Chen J: Eph receptor tyrosine kinases in angiogenesis: from development to disease. Angiogenesis 2004, $7: 17-28$

5. Wang HU, Chen ZF, Anderson DJ: Molecular distinction and angiogenic interaction between embryonic arteries and veins revealed by ephrin-B2 and its receptor Eph-B4. Cell 1998, 93:741-753

6. Flanagan JG, Vanderhaeghen P: The ephrins and Eph receptors in neural development. Annu Rev Neurosci 1998, 21:309-345

7. Pasquale EB: Eph-ephrin promiscuity is now crystal clear. Nat Neurosci 2004, 7:417-418

8. Heroult M, Schaffner F, Augustin HG: Eph receptor and ephrin ligandmediated interactions during angiogenesis and tumor progression. Exp Cell Res 2006, 312:642-650

9. Cheng N, Brantley DM, Chen J: The ephrins and Eph receptors in angiogenesis. Cytokine Growth Factor Rev 2002, 13:75-85

10. Pasquale EB: Eph-ephrin bidirectional signaling in physiology and disease. Cell 2008, 133:38-52

11. Gerety SS, Wang HU, Chen ZF, Anderson DJ: Symmetrical mutant phenotypes of the receptor EphB4 and its specific transmembrane ligand ephrin-B2 in cardiovascular development. Mol Cell 1999, 4:403-414

12. Gale NW, Baluk P, Pan L, Kwan M, Holash J, DeChiara TM, McDonald DM, Yancopoulos GD: Ephrin-B2 selectively marks arterial vessels and neovascularization sites in the adult, with expression in both endothelial and smooth-muscle cells. Dev Biol 2001, 230:151-160

13. Kuijper S, Turner CJ, Adams RH: Regulation of angiogenesis by Eph-ephrin interactions. Trends Cardiovasc Med 2007, 17:145-151

14. Martiny-Baron G, Korff T, Schaffner F, Esser N, Eggstein S, Marme D, Augustin HG: Inhibition of tumor growth and angiogenesis by soluble EphB4. Neoplasia 2004, 6:248-257

15. He S, Kumar SR, Zhou P, Krasnoperov V, Ryan SJ, Gill PS, Hinton DR: Soluble EphB4 inhibition of PDGF-induced RPE migration in vitro. Invest Ophthalmol Vis Sci 2010, 51:543-552

16. Kertesz N, Krasnoperov V, Reddy R, Leshanski L, Kumar SR, Zozulya S, Gill PS: The soluble extracellular domain of EphB4 (sEphB4) antagonizes EphB4-EphrinB2 interaction, modulates angiogenesis, and inhibits tumor growth. Blood 2006, 107:2330-2338

17. Kumar SR, Singh J, Xia G, Krasnoperov V, Hassanieh L, Ley EJ, Scehnet J, Kumar NG, Hawes D, Press MF, Weaver FA, Gill PS: Receptor tyrosine kinase EphB4 is a survival factor in breast cancer. Am J Pathol 2006, 169:279-293

18. Kumar SR, Scehnet JS, Ley EJ, Singh J, Krasnoperov V, Liu R, Manchanda PK, Ladner RD, Hawes D, Weaver FA, Beart RW, Singh G, Nguyen C, Kahn M, Gill PS: Preferential induction of EphB4 over EphB2 and its implication in colorectal cancer progression. Cancer Res 2009, 69:3736-3745

19. Stephenson SA, Slomka S, Douglas EL, Hewett PJ, Hardingham JE: Receptor protein tyrosine kinase EphB4 is up-regulated in colon cancer. BMC Mol Biol 2001, 2:15

20. Liu W, Ahmad SA, Jung YD, Reinmuth N, Fan F, Bucana CD, Ellis LM: Coexpression of ephrin-Bs and their receptors in colon carcinoma. Cancer 2002, 94:934-939

21. Xia G, Kumar SR, Stein JP, Singh J, Krasnoperov V, Zhu S, Hassanieh L, Smith DL, Buscarini M, Broek D, Quinn DI, Weaver FA, Gill PS: EphB4 receptor tyrosine kinase is expressed in bladder cancer and provides signals for cell survival. Oncogene 2006, 25:769-780

22. Berclaz G, Karamitopoulou E, Mazzucchelli L, Rohrbach V, Dreher E, Ziemiecki A, Andres AC: Activation of the receptor protein tyrosine kinase EphB4 in endometrial hyperplasia and endometrial carcinoma. Ann Oncol 2003, 14:220-226

23. Masood R, Kumar SR, Sinha UK, Crowe DL, Krasnoperov V, Reddy RK, Zozulya S, Singh J, Xia G, Broek D, Schonthal AH, Gill PS: EphB4 provides survival advantage to squamous cell carcinoma of the head and neck. Int J Cancer 2006, 119:1236-1248

24. Xia G, Kumar SR, Masood R, Zhu S, Reddy R, Krasnoperov V, Quinn DI, Henshall SM, Sutherland RL, Pinski JK, Daneshmand S, Buscarini M, Stein JP, Zhong C, Broek D, Roy-Burman P, Gill PS: EphB4 expression and biological significance in prostate cancer. Cancer Res 2005, 65:4623-4632

25. Lee YC, Perren JR, Douglas EL, Raynor MP, Bartley MA, Bardy PG, Stephenson SA: Investigation of the expression of the EphB4 receptor tyrosine kinase in prostate carcinoma. BMC Cancer 2005, 5:119

26. Castellano G, Reid JF, Alberti P, Carcangiu ML, Tomassetti A Canevari S: New potential ligand-receptor signaling loops in ovarian cancer identified in multiple gene expression studies. Cancer Res 2006, 66:10709-10719

27. Kumar SR, Masood R, Spannuth WA, Singh J, Scehnet J, Kleiber G Jennings N, Deavers M, Krasnoperov V, Dubeau L, Weaver FA, Sood AK, Gill PS: The receptor tyrosine kinase EphB4 is overexpressed in ovarian cancer, provides survival signals and predicts poor outcome. Br J Cancer 2007, 96:1083-1091

28. Noren NK, Lu M, Freeman AL, Koolpe M, Pasquale EB: Interplay between EphB4 on tumor cells and vascular ephrin-B2 regulates tumor growth. Proc Natl Acad Sci USA 2004, 101:5583-5588

29. Siegal B, Levinton-Kriss S, Schiffer A, Sayar J, Engelberg I, Vonsover A, Ramon Y, Rubinstein E: Kaposi's sarcoma in immunosuppression. Possibly the result of a dual viral infection Cancer 1990, 65:492-498

30. Harlow E, Lane D: Antibodies: A Laboratory Manual. Edited by Harlow E, Lane D. New York, Cold Spring Harbor Laboratory Press, 1988, pp. $274-277$

31. Scatchard G: The attractions of proteins for small molecules and ions. Ann NY Acad Sci 1949, 51:660-672

32. Heijstek MW, Kranenburg O, Borel Rinkes $॥ \mathrm{H}$ : Mouse models of colorectal cancer and liver metastases. Dig Surg 2005, 22:16-25

33. Soltau J, Drevs J: Mode of action and clinical impact of VEGF signaling inhibitors. Expert Rev Anticancer Ther 2009, 9:649-662 